\title{
Response to: Surgical approach for totally implantable venous access port: a full strategy to avoid the percutaneous approach complications
}

\author{
Ulla Klaiber $^{1} \cdot$ Phillip Knebel $^{1}$ \\ Received: 18 March 2021 / Accepted: 24 March 2021 / Published online: 16 April 2021 \\ (C) The Author(s) 2021
}

We thank our Italian colleagues for their interest in our work [1], and we appreciate their statement in favor of surgical cutdown of the coracobrachial or external jugular vein as an alternative in case open cut-down of the cephalic vein fails. We share their opinion that this is a reasonable approach as it offers the chance to prevent puncture-associated complications such as pneumo- and hemothorax effectively. We congratulate Professor Di Carlo and co-workers for their outstanding work on surgical techniques for implantation of totally implantable venous access ports (TIVAP) [2,3]. To our knowledge, outcomes of surgical cut-down of the coracobrachial or external jugular vein for TIVAP implantation have not been investigated within a randomized trial design yet. Therefore, high-quality trials on this topic are needed to gain better evidence as a basis for practice recommendations and guidelines. The conclusion drawn from our results [1] is based on meta-analyzed data from randomized controlled trials in which venous puncture was used as secondor third-line strategy. Considering that complication rates were low in our study even when a percutaneous technique was used, our recommendations were justified and evidence based.

Funding Open Access funding enabled and organized by Projekt DEAL.

Open Access This article is licensed under a Creative Commons Attribution 4.0 International License, which permits use, sharing, adaptation, distribution and reproduction in any medium or format, as long as you give appropriate credit to the original author(s) and the source, provide a link to the Creative Commons licence, and indicate if changes were made. The images or other third party material in this article are included in the article's Creative Commons licence, unless indicated otherwise in a credit line to the material. If material is not included in the article's Creative Commons licence and your intended use is not permitted by statutory regulation or exceeds the permitted use, you will need to obtain permission directly from the copyright holder. To view a copy of this licence, visit http://creativecommons.org/licenses/by/4.0/.

\section{References}

1. Klaiber U, Probst P, Hackbusch M et al (2021) Meta-analysis of primary open versus closed cannulation strategy for totally implantable venous access port implantation. Langenbecks Arch Surg. https://doi.org/10.1007/s00423-020-02057-w

2. Di Carlo I, Barbagallo F, Toro A et al (2005) External jugular vein cutdown approach, as a useful alternative, supports the choice of the cephalic vein for totally implantable access device placement. Ann Surg Oncol 12:570-573

3. Di Carlo I, Pulvirenti E, Mannino M, Toro A (2010) Increased use of percutaneous technique for totally implantable venous access devices. Is it real progress? A 27 -year comprehensive review on early complications. Ann Surg Oncol 17:1649-1656

Publisher's note Springer Nature remains neutral with regard to jurisdictional claims in published maps and institutional affiliations.

Phillip Knebel

Phillip.Knebel@med.uni-heidelberg.de

1 Department of General, Visceral and Transplantation Surgery,

University of Heidelberg, Im Neuenheimer Feld 420,

69120 Heidelberg, Germany 